\title{
Customising DHIS2 for Maternal and Child Health Information Management in Sri Lanka
}

\author{
Dr. M. Subodha Manoj MBBS, MSc \\ Research Fellow, Department of Informatics, University of Oslo, Norway \\ E-Mail address: subodha.manoj@ gmail.com
}

Sri Lanka Journal of Bio-Medical Informatics 2012;3(2):47-54

doi: http://dx.doi.org/10.4038/sljbmi.v3i2.2496

\begin{abstract}
Maternal and Child Health (MCH) is an important component of the primary health care system. MCH systems are developed incorporated with health information systems. Electronic MCH Information Management Systems are emerging and they have proven to improve the quality, efficiency and the cost of medical care. Vendor neutral open source software, such as DHIS2, provides the resources to develop most of the Health Information Management systems. By following open standards; quality, productivity, cost management and data safety can be improved.
\end{abstract}

Keywords - Maternal and Child Health; Open Source; Information Systems, DHIS2

\section{Introduction}

Maternal and Child Health $(\mathrm{MCH})$ Services provide various facilities and programmes organised for the purpose of providing medical and social services for mothers and children. Maternal and child care is a public health service targeting population groups. These population groups are women, infants, children, adolescents and families ${ }^{(1)}$. Many MCH programmes exist worldwide. One key component of all these systems is the $\mathrm{MCH}$ information management system. Information management is essential to ensure the timely availability of information and the evidence needed for policy formulation and for the implementation, monitoring and evaluation of $\mathrm{MCH}$ programmes ${ }^{(2)}$.

$\mathrm{MCH}$ information management systems can be paper based or electronic. Blending of primary care and emerging discipline of public health informatics are slowly but steadily transforms paper based information systems into electronic information systems.

\section{What is Maternal and Child Health?}

Maternal and child health care is a component of primary health care. Primary health care was described in the 1978 Declaration of Alma-Ata as: "essential health care based on practical, scientifically sound and socially acceptable methods and technology made universally accessible to individuals and families in the community through their full participation and at a cost that the community and country can afford to maintain at every stage of their development in the spirit of self-reliance and self determination. It forms an integral part both of the country's health system, of which it is the central function and main focus, and of the overall social and economic development of the community. It is the first level of contact of individuals, the family and community with the national health system bringing healthcare as close as possible to where people live and work and constitutes the 
first element of a continuing health care process"(3).

Maternal and child care is the first point of contact with the health system and involves the provision of integrated, accessible health care services by a variety of providers in the health sector including Midwife, Public Health Nursing Sister and Medical Officer of Health. It includes care given on first contact and it may happen in a clinic setting or at a home visit. Maternal and child care services includes preventative, promotive, curative, supportive and rehabilitation services. These services ${ }^{(2)}$ include maternal care, immunisation, monitoring growth and development, psychosocial development, control of diarrhoeal diseases, acute respiratory infections, nutrition of the pregnant mothers and children, care of the school child, adolescent health and family planning

\section{Issues with MCH programmes}

Recent findings suggest that despite the availability of effective and affordable $\mathrm{MCH}$ services, access to these services remain low. Barriers to access $\mathrm{MCH}$ programmes include ${ }^{(4)}$, geographical distance, financial barriers, socio-cultural / language and ethnicity related barriers, lack of knowledge and awareness and inequalities in quality of care. Due to difficulty in access, coverage of some of these services may remain low ${ }^{(5)}$. Good quality of medical care in both outpatient and inpatient services of health facilities at first referral is essential for a credible and efficient primary healthcare system and some studies emphasise the importance of promotion of $\mathrm{MCH}$ activities like immunisation, breastfeeding and essential new born care in the process of improving child health ${ }^{(6)}$. Some South and East Asian developing countries like Sri Lanka and Thailand have achieved success in $\mathrm{MCH}$ programmes as reflected by their excellent $\mathrm{MCH}$ statistics ${ }^{(7)}$.

Sri Lanka has good MCH statistics ${ }^{(8)}$ reflecting the efficiency and the efficacy of the MCH programme. In Sri Lanka MCH services are carried out by a central government agency called the Family Health Bureau (FHB). Decentralising units are Regional Director of Health Services (RDHS) offices. The current MCH information system is a paper based system. Data collection is done at the point of service delivery. Point of service delivery may be a $\mathrm{MCH}$ clinic or at a home visit. Data is entered to various paper-based forms and reports and sent to FHB through respective MOH or regional epidemiologist office. FHB is responsible for analysing, summarising and reporting of data. FHB receives data from various sources ${ }^{(9)}$. All these factors contribute to the smooth and seamless functioning of the system. Being a paper-based information system it has some inherent problems. They include poor quality of data, gaps in timeliness, poor monitoring of data and feedback. There are practical difficulties faced by the health worker at the periphery. There is a tight schedule for Public Health Midwives (PHM) as they have to do the field work and paper work simultaneously and the PHM spends half the time doing the paperwork. Same data is repeatedly entered by the PHM and the Public Health Nursing Sisters (PHNS). Revising or amending the paper-based system is fairly difficult.

Even though the outcome of the $\mathrm{MCH}$ programme is not hindered by these drawbacks we can expect the system to function even better and to serve the recipient even better if the system is refined to overcome these limitations. The best solution is to introduce an electronic health information management system to the $\mathrm{MCH}$ programme. Some of the developed and developing countries already have $\mathrm{MCH}$ information management systems in place.

\section{Maternal and Child Health information management systems}


MCH information management systems are not developed in isolation. They are developed as a module in primary care or hospital information management system. Research done on $\mathrm{MCH}$ information management is rare. Research done on the effectiveness of health record system on improving quality of maternal and child care is also rare ${ }^{(10)}$. But research has shown that health information management can improve the quality, efficiency and the cost of medical care ${ }^{(11)}$. Open Source Software and Open Standards are two important concepts used in Health information system development. Open Source Software (OSS) systems have paved the way to develop health information systems ${ }^{(12)}$ in developing countries as well as developed countries ${ }^{(13)}$. There are well known benefits of using open source software in health information systems ${ }^{(14)}$. OSS are easy to obtain. They can be downloaded from the internet. There is no fee for licensing, user's only obligation is to honour the open-source license term regarding distribution, derivative work and modifications. Being able to view the source code the developers can understand how the programmer approached the problem. Open-source software is developed by a shared community and for a common purpose. And the product can be used by any one for any related purpose. OSS is vendor neutral. The healthcare organisation can obtain it from any source.

Hospital information systems should be developed complying to open standards in order to harness the benefits of openness ${ }^{(14)}$. It is accepted that lack of complete and comprehensive patient medical record information standards is a major issue on the ability of the healthcare delivery system to enhance quality, improve productivity, manage costs and to safeguard data. Open standards in health information management system is described in terms of interoperability, data comparability and data quality ${ }^{(15)}$.

Interoperability is the ability of one computer system to exchange data with another computer system. To achieve interoperability between different information systems, the healthcare delivery system need to have message format standards. With the use of uniform message format standards, the cost of the healthcare information systems can be lowered and market acceptance can be increased. This would contribute directly to improved quality of care, improved provider productivity, and reduced healthcare costs. Comparability requires that the meaning of data is consistent when shared among different parties. Lack of comparable data can directly impact patient care. Further, the lack of standard vocabularies makes it difficult to study best practices and develop clinical decision support.

The author is in the process of implementing an Open source, Interoperable and Scalable solution for Management of MCH information in Sri Lanka by customising the District Health Information Software Version 2 (DHIS2).

\section{Methodology}

\section{Designing and customisation}

DHIS2 is a free and open-source framework for management of aggregated health information. DHIS2 is mainly used for reporting of aggregated health information from health facility level and this system is implemented in more than 25 countries in Asia and Africa. It has been adopted as the National Health Information system in some countries including Bangladesh and Tanzania ${ }^{(16)}$. 
Designing and development of the $\mathrm{MCH}$ information system was done in a phased manner. The new system was designed maintaining the compatible with the existing $\mathrm{MCH}$ program and existing data flow without any major modifications. The existing $\mathrm{MCH}$ programme handles both individual details of clients and aggregated data. The proposed intervention was directed only for the management of aggregated data. A computer located at the MOH office was connected to the server through internet to access the DHIS2 application which was running in the central server.

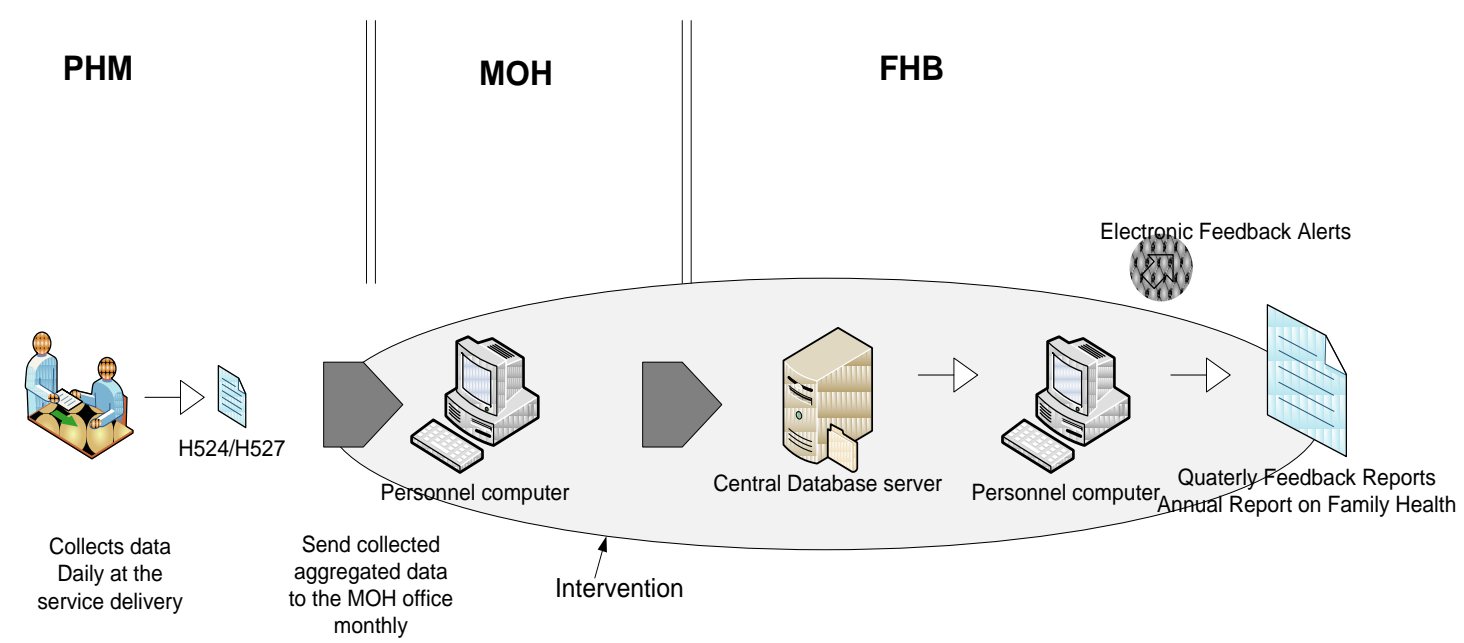

Figure 1. Data flow of the proposed system

This system was designed to cater to data needs at different administrative levels. Field staff requires most of the data collected, while health administrators need only few indicators to take management decisions regarding planning, evaluation and monitoring. $49 \mathrm{MCH}$ indicators are derived from out of the 324 data elements collected at the field level. These indicators are useful at different levels of administration. Collected MCH data is stored in a database and they are represented and analysis using graphical, geographical and tabular formats. Data aggregation and indicator calculation and report generation is automated. Different users have limited access to stored data depending on their level of authorisation.

\section{Piloting}

The customised solution was piloted in one Medical Officer of Health (MOH) area with a population of 125,151, 3 hospitals, 28 clinic centers and 33 Public Health Midwife (PHM) areas. A basic two day training programme was conducted for the $\mathrm{MOH}$ office and field level staff. They were supported with on-site training and supervision during the initial pilot period. $\mathrm{MCH}$ data from each clinic centre and PHM area of the particular $\mathrm{MOH}$ area was entered by the $\mathrm{MOH}$ office staff for two consecutive quarters. The system was verified and customisation was evaluated using this data. 


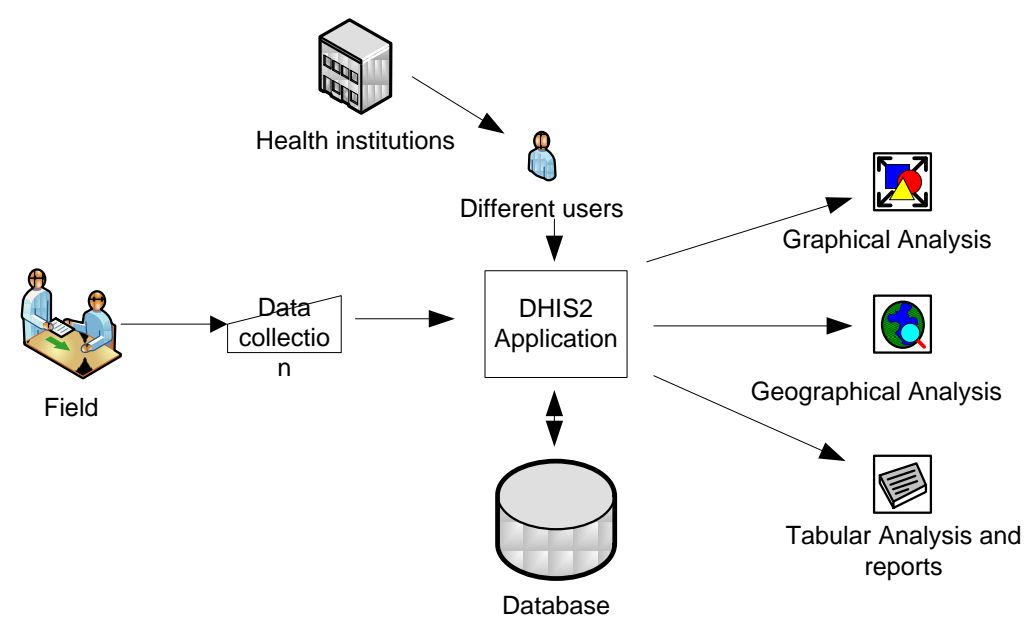

Figure 2. Overview of the proposed system

\section{Evaluation}

The system was evaluated for its correctness and the performance. A workload assessment was done for the $\mathrm{MOH}$ office. Evaluation of the system highlighted the benefits of the new system, including facilities provided for data analysis and ease of data retrieval. Perceivable workload assessment was done based on an interview with different categories of health staff. Being the key officer in the MOH office the Public Health Nursing Sister (PHNS) had perceived a significant reduction of workload after the intervention.

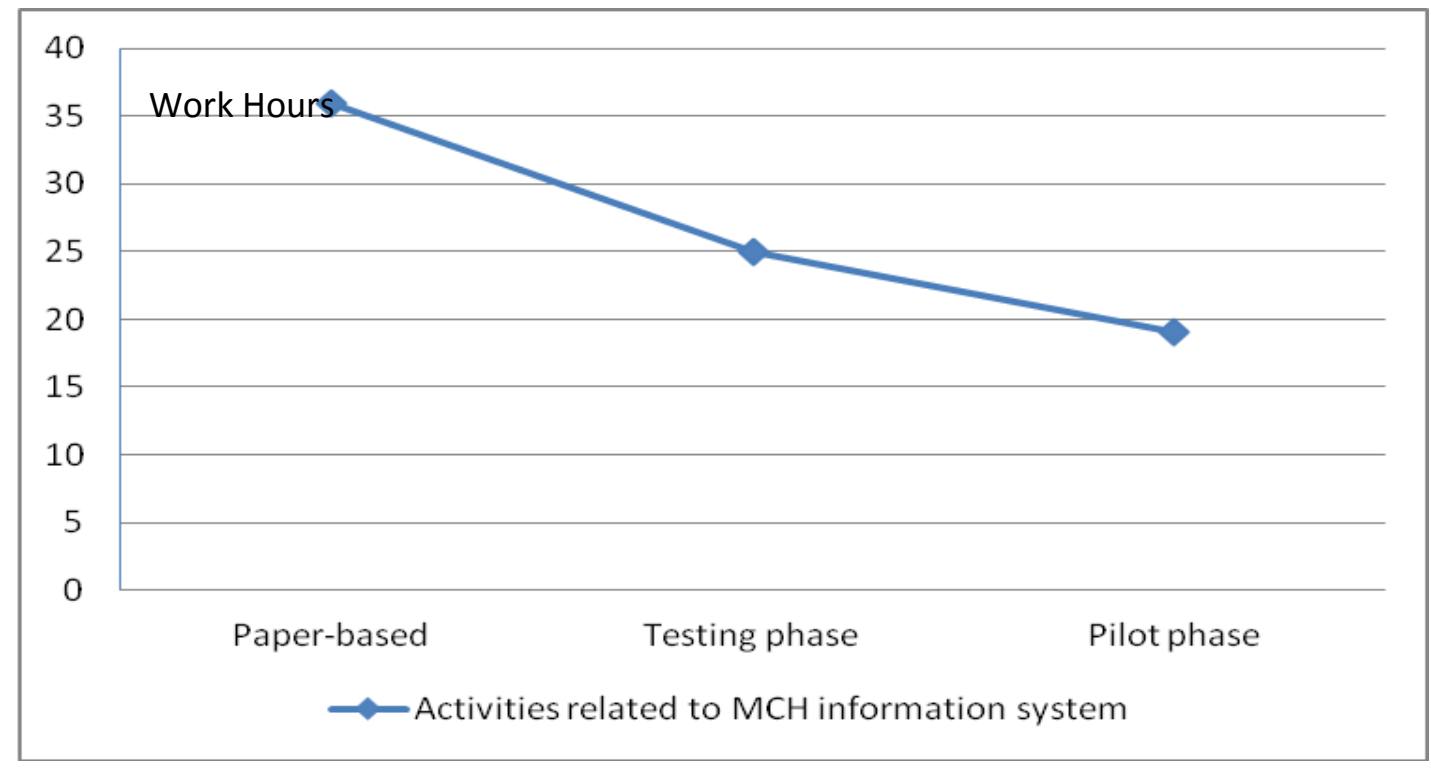

Figure 3. Perceived time spent for MCH information system related activities by PHNS

\section{Feasibility and sustainability}

The new MCH system which is based on DHIS2 framework is freely available for 
customisation, further development and free distribution under modified BSD license $\mathrm{e}^{(17)}$. Ministry of Health has the capacity for customisation and support for DHIS2 application. Community developers are providing regular updates for the software system. Furthermore, the DHIS2 framework is designed to operate in low resource settings and the above pilot project was conducted with the limited resources available at an average $\mathrm{MOH}$ office without any financial or infrastructural support. Technical assistance was provided for customisation, training and a server was provided for hosting of the application.

\section{Conclusion}

Maternal and child health services are an important part of the primary health care service. Information management is essential to ensure the timely availability of information and the evidence needed for policy formulation and for implementation, monitoring and evaluation of $\mathrm{MCH}$ programmes. Despite the availability of effective and affordable $\mathrm{MCH}$ services, access to these services remains low. With the view of providing quality and efficient $\mathrm{MCH}$ care $\mathrm{MCH}$ information management systems are being transformed into electronic form. The Sri Lankan MCH system has proved to deliver a superior service to the public in spite of having some drawbacks in the system that are common to any paper-based information system. Vendor neutral open source software can be used as a low cost solution to transform manual systems to electronic form. With the use of complete and comprehensive information standards; quality, productivity, costs and security of data can be enhanced. The DHIS2 based $\mathrm{MCH}$ Management Information System has proven it's ability for modernising the $\mathrm{MCH}$ information system in a resource limited environment and has the capacity of scaling up.

This MCH Management Information System was not scaled beyond the pilot level. But the DHIS2 framework is recognised in many developing countries in Asia and Africa as a sustainable and user friendly system for managing aggregated health information. It is been adopted by the WHO as a part of their Public health Information tool kit. Furthermore Health Metrics Network (HMN) has supported implementations of DHIS2 based health information systems in many countries ${ }^{(17)}$. It is important to observe and further evaluate the system and give recommendations regarding scale-up of the system.

\section{Acknowledgement}

This project was received financial support from the Health Informatics Society of Sri Lanka.

\section{Reference}

1. The maternal and child health library at Georgetown University. Cited on 23 January 2013. Available from: http://www.mchlibrary.info/guidestopic.html

2. The Family health bureau. Accessed on 23 January 2013. Available from: http://www.familyhealth.gov.lk/

3. Declaration of Alma-Ata., Proceedings of the International Conference on Primary Health Care; 1978 Sep 6-12; Alma-Ata,USSR.Geneva: WHO. Available from:

http://www.who.int/publications/almaata_declaration_en.pdf 
4. Flores G, Abreu M, Olivar MA, Kastner B. Access barriers to health care for Latino children. Archives of Pediatric and Adolescent Medicine 1998; 152(11): 1119. doi: http://dx.doi.org/10.1001/archpedi.152.11.1119

5. Gouws E, Bryce J, Pariyo G, Armstrong SJ, Amaral J, et al. Measuring the quality of child health care at first-level facilities. Social Science and Medicine 2005; 61(3): 613-25. doi: http://dx.doi.org/10.1016/j.socscimed.2004.12.019

6. Sauvarin J. Maternal and Neonatal Health in East and South-East Asia. Bangkok: UNFPA- 2006. Available from: http://www.unfpa.org/upload/lib_pub_file/613_filename_bkmaternal.pdf. Accessed on 28 September 2011.

7. Duke T, Bailey R, Weber MW. Improving the quality of care for children. Indian Pediatrics 2002; 39(6): 523-28.

8. Improving Maternal, Newborn and Child Health in the South-East Asia Region. New Delhi: WHO; 2005. Available from: http://209.61.208.233/LinkFiles/Making_Pregnancy_Safer_Improving_maternal_newbor n_and_child_health.pdf.

9. Maternal and Child and Family Planning Services in Sri Lanka. Family health Bureau Available from: http://www.healthedu.gov.lk/web/index.php?option=com_content \&view=article \&id=88: maternal-and-child-and-family-planning-services-in-sri-lanka\&catid=17:specialarticle $\&$ Itemid $=54 \&$ lang $=$ si Accessed on 28 September 2011.

10. Althabe F, Bergal E, Cafferta M, Gibbons L, Ciapponi A, et al. Strategies for improving the quality of health care in maternal and child health in low- and middle-income countries: an overview of systematic reviews. Paediatric and Perinatal Epidemiology 2008; 1:42-60.

doi: http://dx.doi.org/10.1111/j.1365-3016.2007.00912.x

11. Wu S, Chaudhry B, Wang J, Maglione M, Mojica W, et al. Systematic review: impact of health information technology on quality, efficiency, and costs of medical care. Annals of Internal Medicine. 2006; 144(10): 742-752.

12. McDonald CJ, Schadow G, Barnes M, Dexter P, Overhage JM, et al. Open Source software in medical informatics - why, how and what. International Journal of Medical Informatics 2003; 69(2): 175-184.

13. Gilberto C, Fonseca F. Information policies and open source software in developing countries. Journal of the American Society of Information Science and Technology 2007; 58(1): 121-132.

14. Goulde M, Brown E. Open source: a primer for health care leaders. Oakland (CA): California Healthcare Foundation; 2006. 
15. Chan W, Centiu C, Morris JA, Kurtz M. Uniform data standards for capturing patient medical record information at the point of care. Journal of Healthcare Information Management 1999; 13: 85-96.

16. District Health Information Software 2. Accessed on 21 January 2012. Available from: URL: http://dhis2.org/

17. Braa J, Kanter A S, Lesh N, Crichton R, Jolliffe B, et al. Comprehensive yet scalable health information systems for low resource settings: a collaborative effort in Sierra Leone. In AMIA Annual Symposium Proceedings 2010; 372. 